\title{
DA ASSOCIAÇÃO LIVRE AO DIREITO AO SILÊNCIO: DESAFIOS DA PSICANÁLISE NA ESCUTA DE ADOLESCENTES NAS MEDIDAS SOCIOEDUCATIVAS
}

\author{
JACQUELINE DE OLIVEIRA MOREIRA ID; ANDRÉA MARIS CAMPOS GUERRAID;JULIANA MARCONDES \\ PEDROSA DE SOUZA ID; NATHIELE ARAÚJO OLIVEIRA ID;_LUIZ GUSTAVO GONÇALVES CANUTOIID
}

Jacqueline de Oliveira Moreira ${ }^{1}$

${ }^{1}$ Pontifícia Universidade Católica de Minas Gerais (PUC Minas), Programa de Pós-Graduação em Psicologia, Belo Horizonte/MG, Brasil.

\section{Andréa Maris Campos Guerra ${ }^{2}$ \\ 2 Universidade Federal de Minas Gerais (UFMG), Departamento de Psicologia, Programa de Pós-Graduação em Psicologia, Belo Horizonte/MG, Brasil.}

Juliana Marcondes Pedrosa de Souza ${ }^{3}$

${ }^{3}$ Centro Universitário Metodista Izabela Hendrix, Belo Horizonte/MG, Brasil.

Nathiele Araújo Oliveira ${ }^{4}$

${ }^{4}$ Pontifícia Universidade Católica de Minas Gerais (PUC Minas), Programa de Pós-Graduação em Psicologia, Belo Horizonte/MG, Brasil.

Luiz Gustavo Gonçalves Canuto ${ }^{5}$

${ }^{5}$ Universidade Federal de Minas Gerais (UFMG), Departamento de Psicologia, Belo Horizonte/MG, Brasil.
RESUMO: O presente artigo tem o objetivo de refletir sobre as possibilidades de intervenção junto aos adolescentes que cumprem medidas socioeducativas. Discutiremos o lugar do analista nas medidas socioeducativas, explorando o tensionamento entre o direito de permanecer calado e a questão da associação livre. A partir da literatura científica, buscou-se refletir sobre as possibilidades e desafios da intervenção no campo das medidas socioeducativas tendo a psicanálise como diretriz metodológica, de modo a propor que a escuta e a intervenção analíticas funcionem como orientadores nos atendimentos aos jovens que cumprem medida.

Palavras-chave: adolescência; ato infracional; medida socioeducativa; Psicanálise.

\begin{abstract}
From free association to the right to remain silent: challenges faced by Psychoanalysis in the hearing of adolescents under socio-educational measures. This article aims to reflect on the possibilities of intervention regarding adolescents under socioeducational measures. We will discuss the position of the analyst in this context, exploring the tension between the right to remain silent and the issue of free association. We searched scientific texts for thoughts on the possibilities and challenges faced by interventions regarding adolescents under socio-educational measures, with psychoanalysis as our main methodological guidance, so we could suggest an intervention that works as guidance for these youngsters.
\end{abstract}

Keywords: adolescents; infraction; socio-educational measure; psychoanalysis.

DOI - http://dx.doi.org/10.1590/1809-44142019002011

Todo o conteúdo deste periódico, exceto onde estiver identificado, está licenciado sob uma licença Creative Commons (cc by 4.0) 


\section{A PSICANÁLISE EM FACE DAS CONVOCAÇÕES DO MUNDO CONTEMPORÂNEO}

Em conferência intitulada Linhas de progresso na terapia psicanalítica (1917a/1976), Freud revela que a proposta psicanalítica não se apresenta como um saber fechado e acabado e que é preciso que se esteja atento às imperfeições para aprender mais e "alterar os nossos métodos" (FREUD, 1917a/1976, p. 201). Por outro lado, o autor destaca, no texto Uma dificuldade no caminho da Psicanálise (1917b/1976), as resistências à teoria psicanalítica. Neste texto, Freud apresenta a célebre tese de Haeckel (ASSOUN, 1983) sobre as feridas narcísicas da humanidade e acrescenta a Psicanálise como o terceiro golpe nesse narcisismo, ao afirmar não ser a consciência senhora em sua própria casa.

Com isso, Freud anuncia a permanente posição de estrangeiridade da Psicanálise. O discurso psicanalítico apresenta uma posição de questionamento e de crítica em relação ao saber instituído, no entanto, esta posição não significa uma desconexão com os temas e problemas do seu momento histórico. Ao contrário, dialetiza permanentemente a captura totalizante que tenta silenciar o sofrimento em suas diferentes manifestações. Freud apresenta, por exemplo, o desejo de pensar mudanças nas táticas de atendimento para acolher estes sujeitos traumatizados pela Grande Guerra.

A conjunção desses dois argumentos freudianos produz o efeito e o desejo de se pensarem as exigências dos espaços de atendimento para a clínica da Psicanálise na atualidade. Assim, diante do convite freudiano, buscaremos refletir sobre as possibilidades de intervenção junto aos adolescentes que cumprem medidas socioeducativas. Sabemos que a violência vivida nas trincheiras da Grande Guerra é de ordem diferente da violência urbana que faz a moldura do cotidiano desses adolescentes. Contudo, escutamos o texto freudiano como uma provocação para pensar táticas de intervenção junto a esse grupo, assim como Freud procurou localizar e trabalhar as dificuldades no caminho da escuta e da clínica analíticas articuladas ao contexto da Grande Guerra e suas consequências. Procuramos pensar e atualizar tais questões ao contexto atual da violência urbana e ao dos atendimentos realizados nas medidas socioeducativas de jovens atravessados por ela, sem perder de vista a ética da Psicanálise, tomando a transferência como balizador conceitual.

O campo das medidas socioeducativas deve ser, por excelência, um espaço interdisciplinar, pois o Direito estabelece a "medida", mas esta, para sua execução, demanda um acompanhamento do Serviço Social, da Psicologia, da Pedagogia e de outras disciplinas. A exigência do encontro de diferentes saberes coloca-se a partir da forma como o Sistema Nacional de Atendimento Socioeducativo (SINASE - Lei 12.594/2012), que regulamenta a execução das medidas socioeducativas, foi sendo organizado, pois este sistema prevê a organização das intervenções junto aos adolescentes a partir de três grandes eixos: família, escola e profissionalização.

Todavia, esse espaço de trabalho interdisciplinar não poderia existir sem conflitos, mesmo porque cada campo científico se fundamenta em uma concepção antropológica específica que produz efeitos nas modalidades de intervenção prática. Acreditamos que o conflito seja produtivo e inerente às relações, porque opera a partir da lógica do respeito e do acolhimento às diferenças de cada campo; já a ausência de conflito pode expressar uma posição totalitária e esvaziada da possibilidade de diálogo. Gostaríamos, nessa perspectiva, de refletir sobre um possível conflito que se apresenta no encontro da Psicanálise com o Direito no contexto das medidas socioeducativas.

A famosa frase repetida nos seriados policiais estadunidenses no momento em que o policial declara para o prisioneiro os seus direitos sintetiza o tema que iremos trabalhar: "Tudo que você disser poderá ser usado contra você no tribunal". Segundo Cavalcante (2007), estas palavras "representam o que os norte-americanos chamam de 'The Miranda Warning'":

Em 1966, a Suprema Corte norte-americana decidiu que a confissão feita por Ernesto Miranda, acusado de sequestrar e estuprar uma jovem de 18 anos, aos policiais que o prenderam, não seria válida, uma vez que Miranda não fora informado de seus direitos e garantias constitucionais nem teve a assistência de um advogado (Miranda v. Arizona). (CAVALCANTE, 2007, [s. p.]).

O direito ao silêncio, assim, compõe o grupo de direitos de todo homem acusado, assegurando-lhe sua defesa. A Constituição Federal Brasileira de 1988 também determina os direitos fundamentais do acusado, e, dentre eles, se situa o direito ao silêncio: "LXIII - o preso será informado de seus direitos, entre os quais o de permanecer calado, sendo-lhe assegurada a assistência da família e de advogado" (BRASIL, 1988, Art. 5o).

Spitzcovsky (2005) trabalha as contradições referentes ao direito ao silêncio que aparecem no código, ressaltando que, dentro do tribunal, este direito permanece, mas a redação anterior do Código de Processo Penal previa que o silêncio poderia ser interpretado em prejuízo da própria defesa. A nova redação do artigo modificou esta posição: "Art. 186. Depois de devidamente qualificado e cientificado do inteiro teor da acusação, o acusado será informado pelo juiz, antes de iniciar o interrogatório, do seu direito de permanecer calado e 
Da associação livre ao direito ao silêncio: desafios da Psicanálise na escuta de adolescentes nas medidas socioeducativas

de não responder perguntas que lhe forem formuladas" (Redação dada pela Lei 10.792/2003. BRASIL, 2003).

É interessante notar como, no próprio campo do direito, existem contradições sobre o tema do direito ao silêncio. Todavia, faz-se necessário ressaltar que, ainda que os adolescentes infratores tenham seus direitos e deveres determinados pelo Estatuto da Criança e do Adolescente (ECA), a eles é oferecido acompanhamento psicológico no qual são convidados exatamente a tratar, falando dos impasses envolvidos em seu ato, com vistas à sua responsabilização. Dessa maneira, no campo da Psicologia, em especial orientada pela Psicanálise, a contradição se apresenta sob outro ângulo. Como falar o que ocorrer, diante da ameaça de ter usado contra si o que se disser? Como operar, no nível da responsabilização, com a palavra diante dessa contradição?

\section{A CIÊNCIA PSI E OS DISPOSITIVOS DO DIREITO NO CAMPO DAS MEDIDAS SOCIOEDUCATIVAS}

As instituições responsáveis pela execução das medidas socioeducativas possuem normas que valem para todos, já que se estruturam na perspectiva do universal. Dentre elas, temos a demanda pela elaboração de relatório psicossocial e do Plano Individual de Atendimento (PIA) do adolescente, documentos que deverão ser encaminhados ao juiz após o início do cumprimento da medida socioeducativa e durante sua execução.

Costa et al. (2011) discutem como o relatório psicossocial pode ser construído de modo a não beneficiar unicamente o juiz e ser um instrumento de enriquecimento do processo jurídico e de ampliação da visão dos atores do judiciário sobre a fase de desenvolvimento do adolescente. Os autores afirmam, ainda, que o documento não deve ser elaborado em uma visão apenas avaliativa, mas de modo a devolver a humanidade aos sujeitos dependentes das decisões judiciais e promover uma perspectiva de intervenção psicossocial.

Elaborado para oferecer ao magistrado um maior conhecimento sobre estes sujeitos, subsidiar suas decisões com informações mais qualificadas e, possivelmente, servir como peça de intervenção, sua confecção cabe aos profissionais psicossociais (psicólogos, assistentes sociais e pedagogos integrantes do Judiciário), os quais oferecem suporte para aprofundar o conhecimento sobre o sujeito e sua realidade sociocomunitária e familiar. Contudo, segundo Costa et al. (2011), o que se tem observado é que os adolescentes somente recebem esta avaliação quando se encontram em condição de excepcionalidade, ou seja, quando privados de liberdade.

Quando chamado a responder à demanda jurídica de elaboração desses documentos, o psicólogo/psicanalista se coloca na posição de escuta desse adolescente. A regra fundamental da psicanálise, "Fale tudo o que vier à sua cabeça" (FREUD, 1912/2006), é então evocada. Como, porém, o adolescente poderá falar àquele que, para ele, a princípio, pode vir a ocupar o lugar de representante de uma lei meramente punitiva? Como falar livremente àquele que se sabe ser o responsável por seu relatório, documento que auxiliará o juiz na tomada de decisão por uma medida socioeducativa ou extinção da mesma?

$\mathrm{Na}$ esfera jurídica, esses dispositivos têm por função informar ao judiciário sobre o acompanhamento do adolescente e subsidiar o juiz em suas decisões no processo ao qual este adolescente responde. Espera-se que compreendam comportamentos reincidentes ou indícios de melhora de comportamento, ou seja, o foco é o comportamento deste adolescente após acautelamento, podendo essas observações possibilitar que o Juiz possa tomar decisões mais seguras e informadas.

A existência do relatório, que funciona como instrumento que auxilia o juiz nas suas decisões, reforça no adolescente a ideia errônea de que falar de sua vida é negativo, pois, ao conversar com o psicólogo, esse indivíduo poderia criar provas contra si mesmo que poderiam mantê-lo por mais tempo no cumprimento da medida ou indicar o cumprimento de uma medida mais gravosa. Nesse sentido, quanto menos falar, melhor.

Há uma estranha presunção de que tudo o que o adolescente tem para falar de sua vida é da ordem do agravante da pena, bem como uma falsa conexão que se dá entre a ação de escrever um relatório, o que é registrado, e o agravamento ou prolongamento da pena. Neste ponto, é fundamental destacar a escuta livre, nas palavras freudianas, flutuante, como contrapartida da regra de ouro da associação livre, uma vez que nem tudo o que se escreve no relatório é necessariamente prova contra o adolescente. Impossível, entretanto, não localizar nesse instrumento uma relação de poder, dissimétrica e interessada, que demarca uma das diferenças entre o uso da Psicanálise no consultório e no campo judicial.

Além disso, outro ponto importante é o da não discernibilidade entre fato e fantasia no discurso daquele que fala ao analista, isto é, a igual importância dada à realidade psíquica e à realidade factual. Com isso levado em consideração, modifica-se radicalmente o estatuto daquilo que é dito durante um atendimento, que deixa de se constituir necessariamente como prova factual de um possível ato criminoso. Isso retoma parte da discussão freudiana em $A$ Psicanálise e a determinação dos fatos nos processos jurídicos (1906/1976) sobre uma possível contribuição da Psicanálise nos procedimentos jurídicos no que se refere à produção de provas. De acordo com essa referência, dentro do contexto dos atendimentos em Psicologia, uma confissão não teria, necessariamente, o valor de prova positiva, mas não deve deixar de ser escutada como algo que diz da posição 
inconsciente daquele que fala.

Segundo Lacan, "é com a dimensão da palavra que se cava no real a verdade" (LACAN, 1975/1986, p. 261), mas com ela se introduz também a mentira, a equivocação e a ambiguidade. A resistência provém "da impotência do sujeito em alcançar o domínio da realização de sua verdade" (LACAN, 1975/1986, p. 63). Assim, a palavra falsa é, em última análise, a verdadeira revelação, como no ato falho em que se fala o que não se gostaria - mas se queria - dizer. Nesse sentido, a partir do plano inconsciente, o erro ou o equívoco acabam por encarnar a verdade (LACAN, 1975/1986, p. 300).

Quando solicitados para falar nos atendimentos sobre questões que lhes são subjetivas como suas relações familiares, amigos, angústias, medos, trajetória infracional, questões que tocam no seu envolvimento com a criminalidade , os adolescentes apresentam uma resistência em dizer "tudo o que Ihes vem à cabeça" e respondem "de boa" aos questionamentos que Ihes são feitos, ou seja, simulam uma perfeita adequação às regras. No lugar de responder dizendo tudo o que lhes vem à cabeça, respondem tudo o que supõem que o técnico quer ouvir.

Mesmo acreditando que mentem ou que enganam, acabam por revelar a verdade de sua posição. É essa a discussão que Lacan retoma em 1971: “De onde se interroga a verdade?” (LACAN, 1971/2009, p. 67). Ele lembra, com a lógica clássica, a verdade contida na enunciação "eu minto", cuja escrita revela seu valor contraditório, pois é verdade que o sujeito mente. "Que o inconsciente sempre diga a verdade e minta é, partindo dele, perfeitamente sustentável [...] da verdade, vocês só sabem alguma coisa quando ela se desencadeia [...] rompe sua cadeia [...] quando a verdade se recusa, isso me serve para alguma coisa. É com isso que temos de lidar o tempo todo na análise" (LACAN, 1971/2009, p. 68). É justamente quando algo se rompe e o real surge, que algo da verdade poderá ser escrito como ficção, mito individual para cada sujeito.

Embora o foco do Judiciário esteja na compreensão dos atos infracionais cometidos e no comportamento durante a execução da medida, a equipe técnica pode fazer do espaço de atendimento um meio de revelação e engajamento do sujeito e de sua história. Para interpelar "o pagar de boa", ou seja, a afirmação do adolescente de que pretende cumprir sua medida socioeducativa respondendo ao demandando, mas sem implicação, oferta-se um espaço de escuta em que, pela palavra, o sujeito poderá implicar-se na maneira como trata seu gozo. Sob outra perspectiva, coloca-se em jogo a maneira como o sujeito se engana, pois, antes de ser um atentado ao corpo social, o ato do adolescente volta-se contra ele próprio - e é disso que ele não sabe, nem parece querer saber.

Assim, o adolescente pode até saber o que pode dizer para não se comprometer e conseguir, o mais breve possível, extinguir a sua medida socioeducativa. Por outro lado, se os operadores do sistema mantêm o foco do trabalho na mudança de comportamento, que se dá pela execução com sucesso das intervenções sociopedagógicas, nem sempre será possível o alcance de um novo enlace desse sujeito com sua verdade e com o Outro social por outra via que não a infração.

Diante disso, sustentamos um trabalho orientado pela ética da Psicanálise, que tem como parâmetro a responsabilização de cada um sobre sua forma de gozo. Nas palavras de Lacan, "por nossa posição de sujeito, sempre somos responsáveis" (LACAN, 1965/1998b, p. 873).

\section{A PSICANÁLISE E O ATENDIMENTO AOS ADOLESCENTES AUTORES DE ATO INFRACIONAL: RECORTES DE UMA PRÁTICA}

Figueiredo (1997) discute como é possível lançar mão da Psicanálise em atendimento nos ambulatórios públicos. Para a autora, existem algumas condições fundamentais a esse trabalho, que tem como fundamento a metapsicologia freudiana e o ensino de Lacan. A primeira condição refere-se ao argumento de que a Psicanálise trabalha a partir da realidade psíquica, sendo a fala do sujeito, portanto, de extrema importância. Podemos pensar aqui, também, que esse argumento soluciona em parte o impasse entre a regra da associação livre e o direito do sujeito de não produzir provas contra si mesmo, pois a verdade inconsciente e íntima de um sujeito se impõe e produz efeitos na realidade dos fatos, social e juridicamente partilhada. Assim, convidar um sujeito a falar de si sempre o compromete com seu ato de fala e seus efeitos, mostrando que a realidade é sempre psíquica e que por ela sempre respondemos.

Temos posta a regra fundamental da Psicanálise, "Fale tudo o que Ihe vier à cabeça", como uma das condições do trabalho de escuta dos adolescentes. Essa regra convoca-nos a pensar a segunda condição à qual se refere Figueiredo (1997): a transferência, ao colocar em cena o inconsciente daquele que fala, convoca também o profissional que se encontra em posição de escuta desse sujeito.

A posição do analista consiste justamente em não responder desse lugar transferencial, mas escutá-lo, captá-lo no discurso daquele que lhe dirige a palavra para depois intervir. O que se coloca em cena é a transfe- 
rência do sujeito que fala, isto é, seu inconsciente na forma de resistência, e não o analista. Ao analista, cabe sustentar o lugar de escuta e de causa de desejo, de modo que seja possível operar alguma modificação na posição subjetiva daquele que lhe fala (LACAN, 1958/1998a).

A partir da transferência, o analista poderá calcular as intervenções que se sustentam sempre no caso a caso e têm, como fundamento, "a fala que deve ser privilegiada não como manifestação patológica que exige correção ou resposta imediata, mas como possibilidade de fazer aparecer uma outra dimensão da queixa que singulariza o pedido de ajuda" (FIGUEIREDO, 1997, p. 53).

Diante da demanda do trabalho que protocoliza a atuação dos profissionais, exigindo preenchimento de fichas e prontuários, encaminhamentos diversos e uso de ferramentas metodológicas organizadoras dos serviços, nós, como psicanalistas, somos convocados a fazer outro uso desses procedimentos. Figueiredo (2005) nos lembra que todo esse conjunto de regras poderá auxiliar o profissional a se situar frente ao caso, a fazer suas perguntas e questionamentos com foco na construção de intervenções a partir das indicações de cada sujeito, sendo o trabalho de escuta sob transferência a fonte privilegiada dessas indicações.

Podemos observar, no caso dos adolescentes que cumprem medida socioeducativa, que a regra fundamental da Psicanálise, que convoca o sujeito a falar livremente, encontra resistência. No artigo $A$ dinâmica da transferência, de 1912, Freud já ressaltava o caráter paradoxal do fenômeno, sendo ele ao mesmo tempo condição de tratamento e seu mais forte empecilho. Ali, o autor aponta que, numa análise, a transferência surge como "a mais forte resistência" (FREUD, 1912/2006, p. 94). Também nesse trabalho encontramos a definição clássica de resistência enquanto parada, interrupção do livre fluxo da cadeia associativa que, via de regra, estaria ligada ao fato de o paciente ter pensado algo relacionado àquele que o escuta. Isto é, Freud percebe que o paciente teria transferido algo de si à figura do médico, indicando como solução o simples esclarecimento sobre esse ponto. A contribuição de Lacan (1958/1998a) para esta questão propõe a sustentação do mal-entendido e a condição de fala que o trabalho analítico exige através da não resposta do lugar de suposto saber. Dessa maneira, reenvia a produção analítica para o tratamento do que resta sem sentido e sem simbolização. Podemos igualmente pensar que as manifestações de resistência no contexto dos atendimentos nas medidas socioeducativas se referem ao mesmo fenômeno. Sendo assim, resistência é transferência, cabendo ao técnico manejá-la.

A resistência enquanto fenômeno de interrupção da cadeira associativa extrai sua força de duas fontes principais, de certa organização pulsional já estabelecida (daí seu caráter conservador) e do conflito entre o material inconsciente e a parte consciente do psiquismo, derivando-se daí seu caráter estático, e, ao mesmo tempo, fazendo surgir o silêncio no lugar das palavras e mantendo posições de gozo estabelecidas.

A transferência surge como um compromisso entre a força de resistência e a investigação do trabalho analítico. Freud afirma que "sempre que nos avizinhamos de um complexo patogênico, a parte desse complexo capaz de transferência é empurrada para a consciência e defendida com enorme tenacidade" (FREUD, 1912/2006, p. 95), o que faz com que tenhamos um compromisso entre transferência e resistência: a transferência se transforma em resistência e estanca ou desvia a produção significante, e, a partir daí, passa a ser "defendida com enorme tenacidade". Assim, com Freud e Lacan, podemos dizer que a transferência em sua forma mais poderosa, a resistência, fixa uma forma de gozo quando aquilo de que se falaria, se cala. Evidencia-se, assim, algo da ordem do recalcado ou do real, manifesto na compulsão à repetição. A transferência surge aí como recurso.

Sendo este o caso, é preciso perguntar se, ao recusar-se a falar, estaria o jovem de alguma forma fixado a uma posição na qual os efeitos do trabalho realizado a partir de sua fala poderiam vir a perturbar. Pois, assim, mais que uma recusa em produzir provas legais contra si mesmo, haveria também uma recusa em renunciar a essa modalização na forma de obtenção de gozo, uma recusa em abrir mão do sintoma. Se se trata sempre de um material ligado ao complexo patogênico transferido à figura do analista, falar sobre esse material já seria trabalhar essa resistência. Dessa forma, poderíamos tratar a resistência como parte do material da associação livre, seja ela da ordem do recalcado, do real que insiste ou da ordem da escolha consciente.

Compreende-se também a ideia de Lacan de que a resistência (enquanto parada, interrupção do processo analítico) é sempre resistência do analista, isto é, tratar-se-ia de uma situação em que o analista não soube reconhecer ou considerar aquela produção discursiva do paciente da maneira como deveria. De alguma forma, o analista engana-se ao acreditar que aquele silêncio não quer realmente dizer nada; o silêncio da resistência fala.

Célio Garcia (2009), fazendo alusão ao conceito lacaniano de sujeito suposto saber, denominou como "sujeito suposto poder" a posição do analista diante do adolescente que cumpre medida socioeducativa. Sendo o técnico/analista responsável por informar ao juiz sobre o cumprimento adequado ou não da medida, a ele é também suposto certo poder punitivo. A tentativa de articular as regras e protocolos dos serviços, a orientação da política e a escuta da subjetividade é, para Garcia (2009), uma prática que não está predefinida. Como algo da transferência/resistência desses jovens passa em torno da ideia de poder, a dificuldade surge justamente 
Jacqueline de Oliveira Moreira; Andréa Maris Campos Guerra; Juliana Marcondes Pedrosa de Souza; Nathiele Araújo Oliveira; Luiz Gustavo Gonçalves Canuto

quando o técnico não consegue se desembaraçar desse lugar. A partir do momento em que responde enquanto aquele que detém, seja saber ou poder, confirma essa posição em relação ao jovem. Não há mais associação livre quando já não há analista enquanto semblante de objeto $a$, enquanto causa de livre-associação. Aqui, estamos no império da acusação, do risco da contenção, e não em face da possibilidade da revelação.

Embora possamos admitir que, havendo essa suposição de poder por parte do jovem e que ela é causa de resistência quando o analista responde desse lugar, há ao menos o indicativo de que, ao não responder enquanto detentor de poder punitivo sobre o jovem, o analista torna possível reabrir o campo da associação livre. A suposição de Poder, tal qual a suposição de Saber, é um efeito lógico da transferência e se torna resistência se o analista, no lugar de interrogar, responde desse lugar suposto. Vejamos um caso de operação de subversão dessa posição que foi acompanhado por uma das autoras ${ }^{1}$, e que, por este motivo, é apresentado na primeira pessoa.

José, adolescente de 12 anos, inicia o cumprimento de medida socioeducativa de Liberdade Assistida por envolvimento em um assalto, mas, desde os 11 anos, é acompanhado pelos serviços e programas da assistência social por algumas transgressões cometidas que levaram o Juizado a aplicar medidas protetivas a ele e sua família. Órfão de pai e mãe, o menino reside com a avó materna e uma das irmãs. Não tem convívio com outros familiares e pouco com a irmã mais velha, com quem vive brigando, pois, segundo sua avó, ele não acha correto que esta irmã receba dela qualquer ajuda financeira. Em relação à sua trajetória escolar, cabe dizer que esta foi marcada por confusões e brigas, sendo que, no momento do assalto, José encontrava-se evadido da escola. Segundo a avó, José é bem envolvido com a criminalidade, faz uso de drogas e não gosta de ser controlado: "Ele não me dá notícia da sua vida".

Convocado a cumprir sua medida em liberdade assistida, já no primeiro contato demonstra-se disposto a "pagar" pelo que fez, mas apresenta-se incomodado ao ser convidado a falar. José sequer se senta, anda de um lado para o outro e diz: "Onde tenho que assinar, eu vim e agora já posso ir. Deixa eu assinar aí?" Respondi que tínhamos tempo e que eu gostaria de conversar um pouco com ele. Diante da oferta de uma cadeira para que pudesse assentar-se, José afirma que prefere ficar em pé: "O juiz não me disse que eu tinha que falar com você; ele disse que eu tinha que fazer umas coisas tipo ir pra aula, uns curso". Reafirmei que é importante, antes de fazer os encaminhamentos que o juiz havia lhe dito, ouvir um pouco sobre sua vida. A resposta reiterou sua fala anterior, de que isso o juiz não falou que teria que ser feito, e completou: "se quer que eu volte, me dá logo o vale" (auxílio-transporte). Ao entregar-lhe os vales-transporte, afirmo que estarei esperando por ele na próxima semana.

No atendimento seguinte, o adolescente se recusa a se assentar e diz que não pode perder tempo ali, porque tem "uns corre pra fazer". Questiono o que seriam esses "corre", e ele me diz, com certa ironia: "Ah, você não vai gostar de saber". Digo que me interesso por saber sobre sua vida, e ele retruca dizendo que "não vale a pena", já saindo da sala. Logo depois dessa cena, o adolescente me procura dizendo que não havia pegado o "vale" e que precisava dele para voltar na próxima semana. Eu pergunto: "Vale?". Ele responde: "Pra ir e voltar". Entrego dois vales, como de costume, junto a um papel com a data de seu retorno. Ele, então, diz: "Eu quero quatro". Pergunto por que precisaria de mais dois, e ele responde: "Tá achando que eu não tenho dinheiro pra pagar minhas coisas?". José não pega os vales e sai da sala xingando pela regional, mas leva com ele o papel anotado com a data de seu retorno.

No outro dia, o menino volta à regional acompanhado de um amigo que também cumpre medida, em um horário em que eu não estava. É importante mencionar que, no primeiro atendimento, José foi informado do horário em que me encontraria na regional. Mesmo assim, pergunta sobre mim aos outros profissionais que trabalham nas medidas. Como não era aquele meu horário, os profissionais o questionam sobre a possibilidade de lhe ajudarem de alguma forma. Ele diz que não era nada importante e que voltaria depois.

No outro dia, após receber o recado, ligo para a casa de José, e sua avó me diz que não sabe do seu paradeiro e que é comum que passe as noites fora de casa e depois retorne sem dizer o que estava fazendo. Afirma, ainda, que José está ainda muito envolvido com a criminalidade no seu bairro. Peço a ela que diga ao adolescente que entrei em contato e que estarei esperando por ele no dia e horário combinados.

Na semana seguinte, José chega atrasado para o atendimento e fica esperando para ser atendido. Porém, apesar de o atraso ter sido de sua parte, acha horrível ter que esperar e me diz, assim que o chamo: "Já posso ir embora? Não tenho mais tempo pra ficar aqui." Respondo dizendo que ele não poderia ir embora, que tínhamos algumas coisas para conversar. Ele, então, diz: "Fala logo; o que você quer saber?".

Digo que eu gostaria de entender o que estava acontecendo com ele, com sua vida. José, então, me diz que

1 O caso João, nome fictício, foi acompanhado no ano de 2011 por Juliana Marcondes Pedrosa de Souza, na época técnica da Liberdade Assistida da Prefeitura de Belo Horizonte. Este relato se refere às anotações e reconstruções da própria técnica. 
não é possível parar e pensar, porque, se o fizer, vem o arrependimento. E completa: "A vida do crime é 'vida louca' e não tem muita volta; o negócio é morrer como homem".

"O que é morrer como homem?", pergunto ao adolescente, que responde: "Você tá querendo saber demais; é morrer sem dívida. Agora tá bom, me dá os vale aí". Sai da sala e vai embora.

Entre uma semana e outra, José é apreendido e fica alguns dias no Centro de Internação Provisória. Ao ser liberado, e mesmo antes de ser convocado a retomar o cumprimento da sua medida, vai à regional para me dizer que "está tudo bem" com ele. Quer saber quando vai voltar a cumprir sua medida porque não quer ter problema com o juiz.

Acolho José e digo que o juiz irá enviar uma carta informando sobre seu retorno para o cumprimento da medida, mas que poderíamos conversar um pouco, e pergunto para ele o motivo do seu acautelamento. Ele responde: "Não tô ainda cumprindo medida; por que você quer saber?". Digo a José que eu me interesso sobre o que acontece com ele, e ele responde: "Quando voltar, a gente troca uma ideia".

Depois de um curto período, retomo o acompanhamento com José. Ele diz que não quer voltar a ficar preso, e que, por isso, precisa fazer tudo o que o juiz falou. "Não é assim, você manda um relatório e vê como que eu tô, e aí, depois de seis meses, tô liberado? [...] Tenho que fazer matrícula, uns curso, sair dessa vida".

Digo ao José que há várias maneiras de responder aos encaminhamentos exigidos pelo juiz e que poderíamos descobrir a dele. Assim, aos poucos, do adolescente que se limitava a responder as perguntas de forma bem simples - sim/não/talvez -, José começa a pontuar sua história de vida. Certa feita, resolve contar como se davam os assaltos em que ele se envolvia. Nas cenas descritas, ele está sempre acompanhado por dois homens maiores de idade que ficam "na cobertura" e ele entra e assalta o local. "Eu sou o cara; o povo olha e vê esse moleque e acha que não é nada, mas depois do 'isso é um assalto', tudo muda. Eu tenho dinheiro, respeito; na vida do crime é assim, eu não devo a ninguém; se rola tudo bem, a gente divide e tá tudo certo".

Aos poucos, entre um atendimento e outro, fala de fatos importantes em sua vida. Ao falar do início de sua trajetória infracional, diz que está na vida do crime desde que nasceu. Apesar de não se lembrar, seus familiares Ihe contam que sua mãe o levava quando vendia droga. Usuária de crack, ela morreu, segundo ele, com vários tiros porque devia a um traficante. José me mostra uma tatuagem; pergunto o que está escrito, e ele diz: "Vida louca". Porém, ao lê-la, vejo o nome de sua mãe, e ele completa: "Minha mãe era vida louca". Questiono: "O que é vida louca?", e ele responde: "Vida louca é essa vida aí, do crime". O adolescente se sente incomodado ao falar da sua mãe e conclui: "Não gosto de pensar nela".

Assim, a partir das conversas em torno dos eixos da medida, o adolescente aos poucos vai falando de sua vida. Ele não nega seus atos infracionais; quer cumprir sua medida, mas encontra dificuldade em construir outras saídas para sua vida que sejam diferentes da infração. A vida do crime fascina o adolescente: "Não tenho medo de morrer, só tem que morrer como homem", parecendo haver aqui um semblante que sustenta a posição do jovem imaginariamente vinculada ao crime. Há, porém, podemos assim dizer, dois "tipos" de palavra: a palavra plena e a palavra vazia, ou, conforme Lacan no Seminário 1 (1975/1986), a palavra simbólica e a imaginária. Ambas partem da alienação fundamental do sujeito à linguagem, marcando, a primeira, uma posição sustentada no pacto social, e, a segunda, uma alienação aos significantes mestres da civilização contemporânea.

A palavra pode, então, revelar ou escamotear a verdade em jogo. Assim, em meio à guerra que estoura em sua comunidade, José toma partido de um dos lados e se põe ainda mais em risco. Ele se oferece como um soldado disposto a matar e a morrer. Nesse mesmo período, preciso sair do programa para seguir em outra instituição e passar o caso de José para outro profissional. Como José conhece a equipe, ele me explica que, como na sua vida há muitas mulheres, seria bom que um técnico do sexo masculino pudesse acompanhá-lo. Construo com esse técnico a passagem do caso e então me ausento do serviço.

Depois de um período, tenho notícias de que não foi possível sustentar no serviço o endereçamento de José pelo técnico a quem havia dirigido seu desejo de ser escutado. José teve que dar continuidade ao seu acompanhamento com outra pessoa. Depois, recebo a notícia de que ele havia morrido.

O que vale e o que não vale no cumprimento de uma medida socioeducativa? A regra se faz valer pela letra fria da lei, mas devemos sustentar que é possível pinçar do universal o que é singular a cada caso para fazer valer a escuta do analista nesses espaços. Aqui, percebemos que a questão do valor, que vem das perguntas e impasses em torno do vale-transporte que o levaria aos atendimentos, desliza para a questão de quanto vale a vida daquele que fala ao técnico. Qual o valor daquilo que ele tem a dizer e em quê esses dizeres podem captar o olhar do Outro (de uma forma diferente de quando José atua apontando uma arma)? As respostas "não vale a pena" e "você não vai gostar de saber" vêm no lugar de uma questão que poderia se escrever como "será que você gostaria de saber?", demonstrando a relutância em sentar-se no lugar da dificuldade de colocar-se na posição daquele que recebe do Outro o sinal de sua escuta. Mensagem invertida endereçada a 
Jacqueline de Oliveira Moreira; Andréa Maris Campos Guerra; Juliana Marcondes Pedrosa de Souza; Nathiele Araújo Oliveira; Luiz Gustavo Gonçalves Canuto

si, o "vida louca", ele mesmo, assim como sua mãe o fora, se mostra longe da equivocação que a palavra e a escuta poderiam provocar e se manifesta na forma da injunção superegoica que impõe a José morrer "como homem", sem dívidas, pagando com a vida o preço de sua divisão subjetiva. A medida não foi capaz de tratar a tempo a desmedida de seu gozo mortífero; não foi capaz de convocar a palavra dotada de valor simbólico, que permitiria uma retificação da posição subjetiva do jovem.

O caso de José, o adolescente "entregue à sorte", nos faz refletir sobre a ideia de que uma posição universalista embasada apenas na garantia de direitos e cumprimento de deveres, a simples submissão às regras e protocolos, pode ter como consequência a anulação do sujeito, impedindo-o de construir uma solução para o seu conflito e de se implicar com seu ato.

\section{PARA CONCLUIR}

Ter a subjetividade como orientador no trabalho com os adolescentes em cumprimento de medida socioeducativa não é uma tarefa fácil. Garcia (2000) também aponta a escuta como um desafio para compreender a posição do sujeito que está para além de seus atos, queixas e necessidades. Mas como, então, fazer dessa escuta um orientador da política?

Percebemos que o atendimento desses adolescentes, por vezes, visa apenas à apreensão dos sinais indicativos de comportamentos que fogem ou não às regras e, após examinados, servem de baliza para confirmar diagnósticos, elaborar intervenções e direcionamentos que garantirão o retorno do adolescente ao "mundão". Nessa lógica, a escuta passa a não cumprir mais do que uma função utilitária, que serve para a comunicação em seu caráter informativo, mas deixa de lado o sentido que pode estar por detrás dela.

Segundo Mezêncio (2008), quando o trabalho do psicólogo se configura a partir de um saber que se coloca anterior ao sujeito, põe-se em risco a escuta do que lhe é singular. Qualquer posição universalista embasada puramente na garantia de direitos e cumprimento de deveres segundo regras e protocolos terá como consequência a anulação do sujeito, impedindo-o de construir uma solução para o seu conflito e de se implicar com seu ato. Por isso, nesses espaços, é preciso que o analista possa escutar visando a compreender como o adolescente mesmo que de forma fragilizada, pela via do ato infracional lança ao Outro sua pergunta. Com isso, torna-se possível que o analista passe da posição de suposto poder à de suposto saber, sustentando o convite ao sujeito para falar sobre o que lhe aflige, valendo-se da transferência.

A posição do psicanalista, portanto, não pode coincidir com a função técnica socioeducativa de produção de um saber que definirá o destino do adolescente com vistas à sua reinserção adaptativa. Ela se refere, antes, à posição daquele que, a partir da escuta do singular, sustenta construções nas quais o adolescente esteja implicado enquanto sujeito e se responsabilize por sua posição e escolhas na vida. $O$ analista dá sinal de sua escuta através de seu ato (de um dizer, uma interpretação, um silêncio, um corte), e é fundamental que essa escuta retorne àquele que lhe fala. A implicação em sua própria posição subjetiva é um efeito do trabalho analítico, que implica, em primeiro lugar, o inconsciente que, sob transferência, fala, ainda que pelo ato, quando não pelo sintoma. Para isso, partir da escuta como questão preliminar, e não recuar, se torna, assim, uma tarefa ética.

Recebido em: 8 de outubro de 2015. Aprovado em: 13 de abril de 2016.

\section{REFERÊNCIAS}

\section{Livros}

ASSOUN, P-L. Introdução à epistemologia freudiana. Rio de Janeiro: Imago, 1983.

FIGUEIREDO, A. C. Vastas confusões e atendimentos imperfeitos: a clínica psicanalítica no ambulatório público. Rio de Janeiro: Relume Dumará, 1997.

LACAN, J. De um discurso que não fosse do semblante - 1971 (1971). Rio de Janeiro: Jorge Zahar, 2009. (O seminário, 18).

LACAN, J. Os escritos técnicos de Freud - 1953-1954 (1975). Rio de Janeiro: Jorge Zahar, 1986. (O seminário, 1).

Citações de Freud

FREUD, S. A dinâmica da transferência (1912). Rio de Janeiro: Companhia das Letras, 2006. Obras completas, 10).

FREUD, S. A Psicanálise e a determinação dos fatos nos processos jurídicos (1906). São Paulo: Imago, 1976. (Edição standard brasileira das obras psicológicas completas de Sigmund Freud, 9).

FREUD, S. Linhas de progresso na terapia psicanalítica (1917a). São Paulo: Imago, 1976. (Edição standard brasileira das obras psicológicas completas de Sigmund Freud, 17).

FREUD, S. Uma dificuldade no caminho da Psicanálise (1917b). São Paulo: Imago, 1976. (Edição standard brasileira das obras psicológicas completas de Sigmund Freud, 17). 
Da associação livre ao direito ao silêncio: desafios da Psicanálise na escuta de adolescentes nas medidas socioeducativas

Capítulos de livros

LACAN, J. A ciência e a verdade (1965). In: LACAN, J. Escritos. Rio de Janeiro: Jorge Zahar, 1998b.

LACAN, J. A direção do tratamento e os princípios de seu poder (1958). In: LACAN, J. Escritos. Rio de Janeiro: Jorge Zahar, 1998a.

Artigos de revistas

FIGUEIREDO, A. C. Uma proposta da psicanálise para o trabalho em equipe na atenção psicossocial. Mental, v. III, n. 5, 2005, p. 44-55.

Artigos publicados em revistas eletrônicas

BELLO, L. M. Jovens infratores e a terapia: uma questão para os "observadores da multiplicidade humana". Psicol. cienc. prof., v. 21, n. 4, 2001. Disponível em: http://www.scielo.br/scielo. php?script=sci_arttext\&pid=S1414-98932001000400005\&lng=en\&nrm=iso. Acesso em: 16 jan. 2013.

CAVALCANTE, M. A. L. A Defensoria Pública e a nova exigência do flagrante imposta pela Lei $\mathrm{n}$. 11.449/07. Jus Navigandi, v. 12, n. 1419. Disponível em: http://jus.com.br/revista/texto/9909. Acesso em: 24 maio 2013.

COSTA, L. F. et al. Adolescente em conflito com a lei: o relatório psicossocial como ferramenta para promoção do desenvolvimento. Psicol. estud., v. 16, n. 3, 2011. Disponível em: http:// www.scielo.br/scielo.php?script=sci_arttext\&pid=S1413-73722011000300005\&lng=en\&nrm =iso. Acesso em: 14 jun. 2013.

GARCIA, C. Responsabilidade sem culpa? Cien. Digital, n. 7, 2009. Disponível em: http://www. champfreudien.org/uploads/document/8197ea1dda15b004b68bc32e24ca1307.pdf. Acesso em: 17 jun. 2013.

MEZÊNCIO, M. Adolescentes e o desatino do gozo. Notas para uma conversação no Núcleo de Pesquisa em Psicanálise e Direito do IPSMMG, em 12 de maio de 2008. 2008. Disponível em: http://www.institutopsicanalise-mg.com.br/psicanalise/almanaque/textos/numero3/2.\%20 Adolescentes\%20e\%20o\%20destino\%20do\%20gozo\%20-\%20M\%C3\%A1rcia\%20Mezencio. pdf. Acesso em: 15 jun. 2013.

SPITZCOVSKY, C. O direito constitucional ao silêncio e suas implicações. Jus Navigandi, v. 10, n. 824, 2005. Disponível em: http://jus.com.br/revista/texto/7361. Acesso em: 25 maio 2013.

Leis

BRASIL. Constituição da República Federativa do Brasil de 1988. Presidência da República - Casa Civil - Subchefia para assuntos jurídicos. 1988. Disponível em: http://www.planalto.gov.br/ ccivil_03/constituicao/constituicao.htm. Acesso em: 25 maio 2013.

BRASIL. Código de Processo Penal. Decreto-Lei n. 3.689, de 3 de outubro de 1941. Presidência da República - Casa Civil - Subchefia para assuntos jurídicos. 1941. Disponível em: http://www. planalto.gov.br/ccivil_03/decreto-lei/del3689.htm. Acesso em: 25 maio 2013.

BRASIL. Lei n. 10.792, de 1ㅇ de dezembro de 2003. Presidência da República - Casa Civil - Subchefia para assuntos jurídicos. 2003. Disponível em: http://www.planalto.gov.br/ccivil_03/leis/2003/ |10.792.htm. Acesso em: 25 maio 2013.

\section{Jacqueline de Oliveira Moreira}

Professora do Programa de Pós-Graduação em Psicologia, Pontifícia Universidade Católica de Minas Gerais (PUC Minas), Belo Horizonte/MG, Brasil. jackdrawin@yahoo.com.br

Bolsista Produtividade CNPq, Fapemig Edital 01/2017.

\section{Andréa Maris Campos Guerra}

Professora do Departamento de Psicologia, Programa de Pós-Graduação em Psicologia, Universidade Federal de Minas Gerais (UFMG), Belo Horizonte/MG, Brasil. andreamcguerra@gmail.com

Bolsista Produtividade CNPq, Fapemig Edital 01/2017.

\section{Juliana Marcondes Pedrosa de Souza}

Professora do Curso de Graduação em Psicologia, Centro Universitário Metodista Izabela Hendrix, Belo Horizonte/MG, Brasil.juliana.marcondes@yahoo.com.br

\section{Nathiele Araújo Oliveira}

Doutoranda no Programa de Pós-Graduação em Psicologia, Pontifícia Universidade Católica de Minas Gerais (PUC Minas),Belo Horizonte/MG, Brasil. nathiele@task.com.br

Bolsista Capes

\section{Luiz Gustavo Gonçalves Canuto}

Graduado pelo Departamento de Psicologia, Universidade Federal de Minas Gerais (UFMG), Belo Horizonte/MG, Brasil. luizgcanuto@gmail.com 